\title{
Action Research Revelations: The Challenges and Promises of Implementing Informal STEM Experiences in K-12 School Settings (Work in Progress, Diversity)
}

\section{Mr. Amari T. Simpson, University of Illinois at Urbana - Champaign}

Amari T. Simpson is a third-year Ph.D. student at the College of Education at the University of Illinois. He has worked as a STEM educator in Boston for two years, and his research interest centers on STEM pre-college program effects on students. He currently serves as a Research Assistant in the College of Engineering. He received a Bachelor's degree in psychology from Middlebury College and a Master's degree in curriculum and teaching in science education from Boston University.

\section{Lara Hebert, University of Illinois at Urbana - Champaign}

Serves as the Outreach and Public Engagement Coordinator for The Grainger College of Engineering. She brings to this position and this initiative expertise in teacher education and curriculum design.

\section{Dr. Luisa-Maria Rosu, University of Illinois at Urbana - Champaign}

Luisa-Maria Rosu is the Director of I-STEM (Illinois Science Technology Engineering and Mathematics) Education Initiative and a Research Associate in the Center for Innovation in Teaching and Learning at University of Illinois Urbana-Champaign. A former mathematics teacher, elementary through college, her interests evolved from teachers' professional knowledge and continuing education to the quality of teaching and the evaluation of STEM programs in higher education.

In 2014, she received a CORE Early Career Fulbright U.S. scholar award for the proposal Investigations of Quality Criteria in STEM Teacher Education and in 2016, she received the YWCA leadership award for STEM education.

Luisa received her Ph.D. in Continuing Teacher Education from the University of Illinois at UrbanaChampaign in 2010. She also holds an M.A in Applied Mathematics from the University of Southern California (2000) and an M.S. in Real and Complex Analysis from the University of Bucharest, Romania (1996).

\section{Dr. Meagan C. Pollock, Engineer Inclusion}

Dr. Meagan Pollock envisions a world where personal and social circumstances are not obstacles to achieving potential, and where kindness, inclusivity, and conservation prevail. As an engineer turned educator for diversity, equity, and inclusion, Meagan focuses on engineering equity into education and the workforce. An international speaker, teacher, engineer, and equity leader, her mission is to provide services, tools, and resources that inspire awareness and initiate action. Learn more at EngineerInclusion.com

Dr. Lynford Goddard, University of Illinois at Urbana - Champaign 


\title{
Action Research Revelations: The challenges and promises of implementing informal STEM experiences in K-12 school settings (Work in Progress, Diversity)
}

\begin{abstract}
Catalyzing Inclusive STEM Experiences All Year Round (CISTEME365) is a multi-year, multi-pronged project funded by the National Science Foundation (NSF). We worked with K-12 school educators to improve their understanding and promote practices that purposely influence students' science, engineering, technology, and mathematics (STEM) interests and career trajectory. We also supported creating and implementing out-of-school STEM clubs that offer students inquiry-driven engineering design and other hands-on STEM experiences throughout the school year. As part of our larger project goals, we tasked a networked community of middle/high school teachers, counselors, and administrators to develop action research projects to improve STEM equity within their schools. We provide initial findings on school educators' experiences and perspectives implementing informal STEM learning within their schools through initial coding and analysis of document materials and transcripts. These materials reveal how unique school characteristics (i.e., support from multiple school educators, clear STEM club leadership roles, and intentional recruitment strategies) hinder or aid in successfully implementing informal STEM learning opportunities. With the COVID-19 pandemic unfolding, some school educators revealed the difficulty of setting up and transitioning their STEM club to a virtual format. Other school educators also remarked how shifts in their educator mindsets from our CISTEME365 STEM equity content led to reimagined instructional strategies that supported their students' STEM interests and awareness. Our study highlights the power of action research and a community of practice for implementing school-based, informal STEM opportunities. By exposing school educators to a broader set of STEM career pathways, emphasizing the field of engineering, our work aims to promote a pluralistic understanding of STEM career pathways for both K-12 educators and students. This material is based upon work supported by the NSF under Grant No. 1850398.
\end{abstract}




\section{Introduction}

The fields of science, technology, engineering, and mathematics (STEM) experience ongoing racial and ethnic diversity issues that are well documented in the literature [1]. Compared to their peers in STEM degrees and careers, Black, Latino, first-generation, women, and low-income students have been historically underrepresented in STEM in the United States (U.S.) [1]. These disparities impact the well-being of society, especially those who have been marginalized, and these inequities will continue to lead to long term consequences for the U.S. job market unless educators and policymakers address issues of STEM diversity and access using a multi-faceted approach.

A wide array of interventions have been implemented to address systemic barriers. Ranging from informal STEM experiences (e.g. after-school activities and maker spaces) [2], [3] to formal STEM K-12 curriculum [4]-[6] and collegiate courses [7]-[9], these various approaches have helped to make STEM learning more accessible for women and minoritized students. Hands-on and informal STEM activities affect identity development [10]-[12]. When executed well, these interventions can increase STEM knowledge and impact STEM major and career inequities [10], [13]. In these settings, school educators play a crucial role in developing students' interest in STEM and increasing diversity in STEM courses, majors, and careers.

Recently, teacher training and state-based reforms have focused on increasing students' awareness of STEM. The Next Generation Science Standards (NGSS) introduced and integrated engineering principles and practices throughout science classrooms in the U.S. These design and project-based efforts have been slow to take hold in middle- and high- school settings, especially in under-resourced schools serving high proportions of minoritized students [4]-[6]. This opportunity gap grows more expansive with limited access to out-of-school enrichment opportunities, like STEM after-school activities and summer camps [2], [3]. School counselors play the role of gatekeepers when it comes to STEM enrichment opportunities, having a tremendous effect on trajectories to STEM majors and careers long-term [14], [15]. Research also shows that the career guidance offered by counselors is negatively affected when counselors have limited knowledge of engineering and the skills it involves [19], [16]. We believe it is important to engage this untapped school profession to meaningfully address racial and gender disparities in STEM [17]-[19].

\section{Program Description}

Catalyzing Inclusive STEM Experiences All Year Round (CISTEME365) is a three-year, three-pronged approach aimed at increasing access to informal STEM learning opportunities for underrepresented students throughout the state of Illinois (see Figure 1 in Appendix A). The first intervention and the primary focus of this paper, is to facilitate professional learning opportunities for up to eight school-based teams each year. Each team includes at least one counselor, one teacher, and one other key stakeholder. These school teams work together throughout the year on issues of STEM inclusion, diversity, equity, and access, using a research-based curriculum of National Alliance for Partnerships in Equity. School teams engage in year-round professional development that addresses STEM equity, inclusion, and access strategies plus engineering content knowledge. Our second intervention supports the school teams in launching and sustaining out-of-school-time STEM clubs. Each site receives 
engineering kits for unique, technology-rich experiences that school teams implement in the clubs. Our third intervention offers access to scholarships for STEM Club students to participate in STEM summer camps at our home institution. Through the STEM club and the STEM summer camp environments, students gain core skills and knowledge aligned with Next Generation Science Standards (NGSS) and STEM workplaces (e.g. engineering design, applying technical knowledge to solve problems, and hardware/software integration).

School educators' professional learning often focuses on instructional practices, and it is rare for knowledge to diffuse across school roles, settings, or district boundaries [20]. Research points to a positive effect on students' achievement when educators' professional practices are collaborative, inquiry-based, and sustainable, and professional learning is content-focused [20], [21]. Our professional development intervention combines the well-grounded practices of action research and that of participation in a community of practice [22], [23]. School Teams attend a 2-week summer institute where they spend time engaged in electrical engineering projects that they will later implement with their STEM clubs. The other half of the time equips educators with research-based, strategy-driven content about stereotypes, bias, and micro-messaging that can limit students' pursuit and success in STEM pathways [24]. Content on growth mindset, affirming micro-messages, and self-efficacy introduces principles related to improving STEM inclusion, access, and equity. This content prepares participants for their action research projects which challenge participants to apply their new knowledge and use data-informed-decision-making to improve STEM access and equity for their students.

At the end of the institute, school teams have begun to think about initiating a STEM Club, identifying the focus of their action research projects, and have built relationships across school teams. This network of teams focused on the common issue of STEM equity becomes a Networked Improvement Community (NIC) that continues to meet monthly during the school year. A Networked Improvement Community (NIC) brings multiple individuals (or teams) together from across a variety of contexts to address a common problem [22]. When implemented well, this cross-institution model for change has demonstrated larger and more rapid shifts in practice than when teams or organizations pursue these changes on their own [22]. Action research is a component of a successful NIC, offering educators an opportunity to tackle real-time, emerging issues using inquiry-based techniques of researchers [23]. In our case, the action research projects provided a structure for individual participants or teams to identify a specific STEM equity and access strategy that they discussed during the summer institute to strategically implement in their school or STEM club setting. They also identify a method for measuring the impact of these efforts. The individual action research efforts within a NIC system honors the diversity of members' experiences and their contexts, allowing for unique interventions to address a shared problem [22]. NICs regularly meet to report individual progress as well as troubleshoot issues experienced by the participating members. By doing this work jointly, progress can be made in addressing persistent problems in education.

During our first year, we worked with thirteen educators from five schools during the summer and throughout the school year. This year of implementation was interrupted in early spring due to the COVID-19 pandemic. Even so, we did our best to remain in contact with the school teams to support them through this trying time and to continue to learn from them about the outcomes of CISTEME365 participation. 


\section{Study Design and Methods}

To gain insight into the effects of our professional learning model, we are investigating the following questions:

- What did action research projects reveal about the way schools implement informal STEM learning opportunities for traditionally underrepresented students?

- What takeaways from the action research process can inform or improve other informal STEM learning initiatives, in or out of schools?

\section{Data Collection}

To begin examining these questions, we collected and reviewed transcripts from the final action research project presentations and reports from four of the five participating schools. The 5 th school was unable to continue engagement once the pandemic began. Participants presented their final action research projects during the final NIC virtual meeting (May 2020) using slide presentations and Zoom web conferencing platform. Presentations were recorded, as well as the discussion that occurred as the participants discussed each action research presentation. Additionally, some participants submitted a final report using a template provided by National Alliance for Partnerships in Equity, where participants shared information on their action research issue, strategies applied, number of students reached, results, reflections, goals for next year, and other additional information (see Figure 2 in Appendix A). Additional data have been collected throughout the project that will provide added content for analysis in the future, especially as it relates to the findings from this preliminary study. These data include student and school team surveys, focus group interviews, and artifact collection and review.

From the four schools (1 middle and 3 high schools) that participated in the May action research presentations, we had eight participants, including STEM teachers $(n=3)$, counselors $(n$ $=3$ ), and other school personnel $(n=2)$. One participating school was located in a majority white small town (91\% white, 17\% low-income) and three were located in a majority Black and Latinx urban community (96\%-99\% Black and/or Latinx, 89\%-97\% low-income) [25].

\section{Recruiting}

School teams were recruited primarily from schools that serve a diverse population of students from throughout the state of Illinois with an interest in improving STEM participation of traditionally underrepresented populations. Interested school teams applied to participate with a letter of support from a school administrator, and committed to launch or expand a STEM club and assist in nominating students to attend STEM summer camps. Five schools provided school teams for the 2019-2020 school year. Several additional schools expressed interest prior to the summer institute, but they chose to delay their participation to a future date. Each participant received a $\$ 1,200$ stipend plus housing and travel costs for the summer institute. Each school received $\$ 3,000$ engineering curriculum and materials for supporting up to 50 students in STEM clubs plus an additional $\$ 1,500$ for flexible spending toward STEM-Club activities (e.g., 3D printer, virtual reality headset, etc.). An ethics review board approved our research design, and we received consent to participate in the research from each participant. 


\section{Data Collection and Analysis}

This study used qualitative methods for data collection and analysis. When the projects were presented during the final scheduled NIC session, they were recorded and transcribed. If participants were unable to share their presentation during the scheduled NIC, a separate presentation time was scheduled with researchers, and these sessions were recorded as well. For each school site, we completed video and audio recordings of all action research projects in addition to generating handwritten notes. Using transcribed audio recordings and action research project descriptions, two members of the CISTEME365 team employed an open and axial coding process to independently identify patterns across the action research projects. We performed subjective intercoder checks for reliability [26]. As more data are collected, this coding structure will continue to evolve [27].

\section{Preliminary Findings}

Preliminary findings revealed significant disruptions in implementing informal STEM opportunities due largely to the isolation resulting from COVID-19 and the nation's unrest over racism and police brutality occurring at a time when school team members had planned to complete their action research processes. Despite hurried or incomplete action research processes, we identified patterns pointing to the unique characteristics of school culture and leadership that facilitate (or hinder) the successful implementation of informal STEM learning opportunities. Additional findings point to broadening understandings of STEM participation and the strengths and challenges of the action research process. In this early stage of analysis, five themes stand out as important for further analysis in this first year of implementation and beyond. We discuss each in more detail below.

The autonomy of the action research process was a prominent theme throughout. The action research process provided a myriad of ways for participants to take action and to study those actions, all with an intent to impact STEM equity and inclusion. A music instructor presented her students with the neuroscience evidence that ability and knowledge are developed through effort and practice (growth mindset) rather than something you are born with (fixed mindset). An instructional coach worked with a group of chemistry teachers on providing feedback that's specific and process-focused. A college and career counselor applied their new knowledge of what constitutes STEM and provided field trips to a wider range of businesses, identifying the STEM skills present in different contexts. One school team moved from 4\% women in STEM classes to 50\% women involved in their STEM Club through strategic recruitment by the counselor, using a variety of data to identify potential candidates. Action research process's flexibility allowed each individual to identify a strategy that mattered most to their own context. In this quote, a high school college and career counselor describes the reasoning behind her action research project choices,

I wanted to bring more STEM exposure to our school and to help students see what I learned over the summer, and that is that STEM comes in every shape and form...STEM is in so much that we do everyday.

COVID-19 interruptions put a halt to multiple projects. The STEM Club field trip to our university campus for an engineering fair was canceled, participants were unable to obtain 
survey responses for their action research projects to measure changes or impact of the intervention, and one STEM Club that struggled to get started never got the chance to meet. Despite this, the flexibility of the action research projects offered new questions to study when teaching moved to virtual. The instructional coach mentioned above modified her action research focus to be about online engagement, allowing her to work with teachers on strategies for giving feedback and designing project-based learning for a virtual environment. The data she compiled indicated that while student attendance and engagement schoolwide was declining, the teachers she coached had steady and even increasing engagement.

School culture and systemic issues were mentioned often. For some, the challenges came in the inability to implement a specific tool in one school while other neighboring schools experienced a different set of policies and expectations. Another project surfaced data that revealed unbalanced Chemistry classrooms, with some classes having significantly larger proportions of students with learning differences, a systemic factor impacting student engagement online. Across multiple sites, the role of leadership was evident, with some teams leading schoolwide professional development or student events on topics learned during the summer institute while other schools experiencing challenges with keeping school teams together and gaining leadership buy-in and support for STEM Club activities. In describing a list of interruptions and challenges that led to her action research focus, one participant reported,

We started the year with a new principal, a new assistant principal, and about 50\% new staff. So this led to my reasoning for wanting to look at the perceptions of the adults as it relates to STEM and how it impacts student participation. Because I really feel like the culture and the climate in the building and the buy-in for the club was extremely low.

We noticed that interpretations of the action research processes varied, some of which came from the flexibility allowed by the process, but we also identified some of this variation due to a lack of clarity delivered by us as program leaders. Some participants used the action research projects to track already occurring activities, rather than specifically taking a new action based on learning from the summer institute. Some were more intentional about data collection than others. Most waited until the last minute to design and implement their action research projects rather than implementing new strategies over time.

Last but not least, the action research process produced new questions. We hope that this is an indication that this practice of action research will endure beyond the life of CISTEME365. For example, one teacher was surprised by high rates of student agreement with, "You can do things differently, but the important parts of who you are can't be changed." As a result, she wants to further study what students identify as these unchangeable "important parts." Another participant who experienced challenges with buy-in and follow-through from other adults in the building is now wondering how to get more school leaders and families to understand their roles in STEM diversity, equity, and access.

\section{Conclusion and Takeaways}

We acknowledge that our participation numbers are small and therefore our findings are not generalizable beyond our program participants, but we learned much in year one that helped to inform the design of year two. We have been more purposeful in year two with scheduling and 
support provided throughout the action research process, including scaffolded steps and one-on-one coaching. Rather than a single dose of intensive professional development in the summer, we spread the learning throughout the year, providing greater opportunity to try out strategies in between the professional development sessions. We also required a stronger commitment from school leaders to provide the time for school teams to meet and to attend professional development. Despite the challenges experienced in 2019-2020, we see strong potential in this multi-pronged approach of tackling STEM equity and inclusion. Teachers, counselors, and instructional coaches were all able to find their own place within the action research process. They pursued their own questions that mattered to them, at that particular time and in that particular setting. Whether they were pursuing questions of their students' self-efficacy or coaching other teachers to offer more meaningful and inclusive feedback, each moved the DEI needle in their own way. In 2020-2021, we are seeing a difference in levels of participation, despite the need to do everything virtually, and we are looking forward to the next round of action research project presentations to see what more we can learn. 


\section{References}

[1] M. K. Eagan, S. Hurtado, M. J. Chang, G. A. Garcia, F. A. Herrera, and J. C. Garibay, "Making a difference in science education: The impact of undergraduate research programs," Am. Educ. Res. J., vol. 50, no. 4, pp. 683-713, Aug. 2013, doi: 10.3102/0002831213482038.

[2] G. J. Duncan and R. J. Murnane, Eds., Whither opportunity? rising inequality, schools, and children's life chances. New York : Chicago: Russell Sage Foundation ; Spencer Foundation, 2011.

[3] National Center on Afterschool and Summer Enrichment (NCASE), "Why Summers Matter," p. 6, 2016.

[4] Change the Equation, Ending the Double Disadvantage: Ensuring STEM Opportunities in our Poorest Schools. 2017.

[5] Next Generation Science Standards (NGSS) Lead States, Next Generation Science Standards: For states, by states. 2013. doi: 10.17226/18290.

[6] National Research Center, A Framework for K-12 Science Education: Practices, Crosscutting Concepts, and Core Ideas. 2011. doi: 10.17226/13165.

[7] K. Sacco, J. H. Falk, and J. Bell, "Informal Science Education: Lifelong, Life-Wide, Life-Deep," PLOS Biol., vol. 12, no. 11, p. e1001986, Nov. 2014, doi: 10.1371/journal.pbio.1001986.

[8] S. Allen and K. Peterman, "Evaluating Informal STEM Education: Issues and Challenges in Context," New Dir. Eval., vol. 2019, no. 161, pp. 17-33, 2019, doi: 10.1002/ev.20354.

[9] A. C. Fu, A. Kannan, and R. J. Shavelson, "Synthesis of Issues and Future Directions.," New Dir. Eval., vol. 2019, no. 161, pp. 125-131, 2019.

[10] N. S. King and R. M. Pringle, "Black girls speak STEM: Counterstories of informal and formal learning experiences," J. Res. Sci. Teach., vol. 56, no. 5, pp. 539-569, 2019, doi: $10.1002 /$ tea.21513.

[11] R. Dou, Z. Hazari, K. Dabney, G. Sonnert, and P. Sadler, "Early informal STEM experiences and STEM identity: The importance of talking science," Sci. Educ., vol. 103, no. 3, pp. 623-637, 2019, doi: 10.1002/sce.21499.

[12] T. Roberts et al., "Students' perceptions of STEM learning after participating in a summer informal learning experience," Int. J. STEM Educ., vol. 5, no. 1, p. 35, Sep. 2018, doi: 10.1186/s40594-018-0133-4.

[13] J. A. Banks et al., "Learning in and out of school in diverse environments. Lifelong, life-wide, life-deep.," p. 40.

[14] C. D. Schmidt, G. B. Hardinge, and L. J. Rokutani, "Expanding the School Counselor Repertoire Through STEM-Focused Career Development," Career Dev. Q., vol. 60, no. 1, pp. 25-35, Mar. 2012, doi: 10.1002/j.2161-0045.2012.00003.x.

[15] American School Counselor Association, ASCA National Standards for Students. 2004.

[16] M. Pollock, "Attracting Future Engineers: Best Practices from K-12 Counselor Professional Development, 2008-2012," Atlanta, GA, 2013.

[17] A. A. Cox and C. C. Lee, "Challenging Educational Inequities: School Counselors as Agents of Social Justice," in Counseling for social justice, 2nd ed, Alexandria, VA, US: American Counseling Association, 2007, pp. 3-14.

[18] D. Griffin and S. Stern, "A Social Justice Approach to School Counseling," J. Soc. Action Couns. Psychol., vol. 3, no. 1, Art. no. 1, Apr. 2011, doi: 10.33043/JSACP.3.1.74-85.

[19] Virginia Demonstration Project, "Evaluation report summary," 2010. 
https://stem.wm.edu/virginia-k12-stem-outreach/virginia-demonstration-project/evaluation/ (accessed Jun. 19, 2020).

[20] K. Zeichner, "Educational action research," in Handbook of action research: Participative inquiry and practice, P. Reason and H. Bradbury, Eds. Sage, 2001, pp. 273-283.

[21] Learning Forward, Standards for professional learning: Quick reference guide. 2011.

[22] Bryk, A. S., Gomez, L. M., Grunow, A., \& LeMahieu, P. G. and Bryk, A. S., Gomez, L. M., Grunow, A., \& LeMahieu, P. G., Learning to improve: How America's schools can get better at getting better. Harvard Education Press, 2015. Accessed: Jun. 19, 2020. [Online]. Available: https://www.carnegiefoundation.org/resources/publications/learning-to-improve/

[23] P. Reason and H. Bradbury, "Introduction," in The Sage handbook of action research: participative inquiry and practice, SAGE Publications, 2008, pp. 1-10.

[24] C. Parker, C. Morrell, C. Morrell, and L. Chang, "Shifting Understandings of Community College Faculty Members: Results of an Equity-Focused Professional Development Experience," J. Fac. Dev., vol. 30, no. 3, pp. 41-47, 2016.

[25] "Illinois Report Card." https://www.illinoisreportcard.com/ (accessed Apr. 19, 2021).

[26] V. Braun and V. Clarke, "Using thematic analysis in psychology," Qual. Res. Psychol., vol. 3, no. 2, pp. 77-101, 2006.

[27] J. M. Corbin and A. Strauss, "Grounded theory research: Procedures, canons, and evaluative criteria," Qual. Sociol., vol. 13, no. 1, pp. 3-21, 1990. 
Appendix A

Figure 1.

The targeted programming features of Catalyzing Inclusive STEM Experiences All Year Round (CISTEME365) program

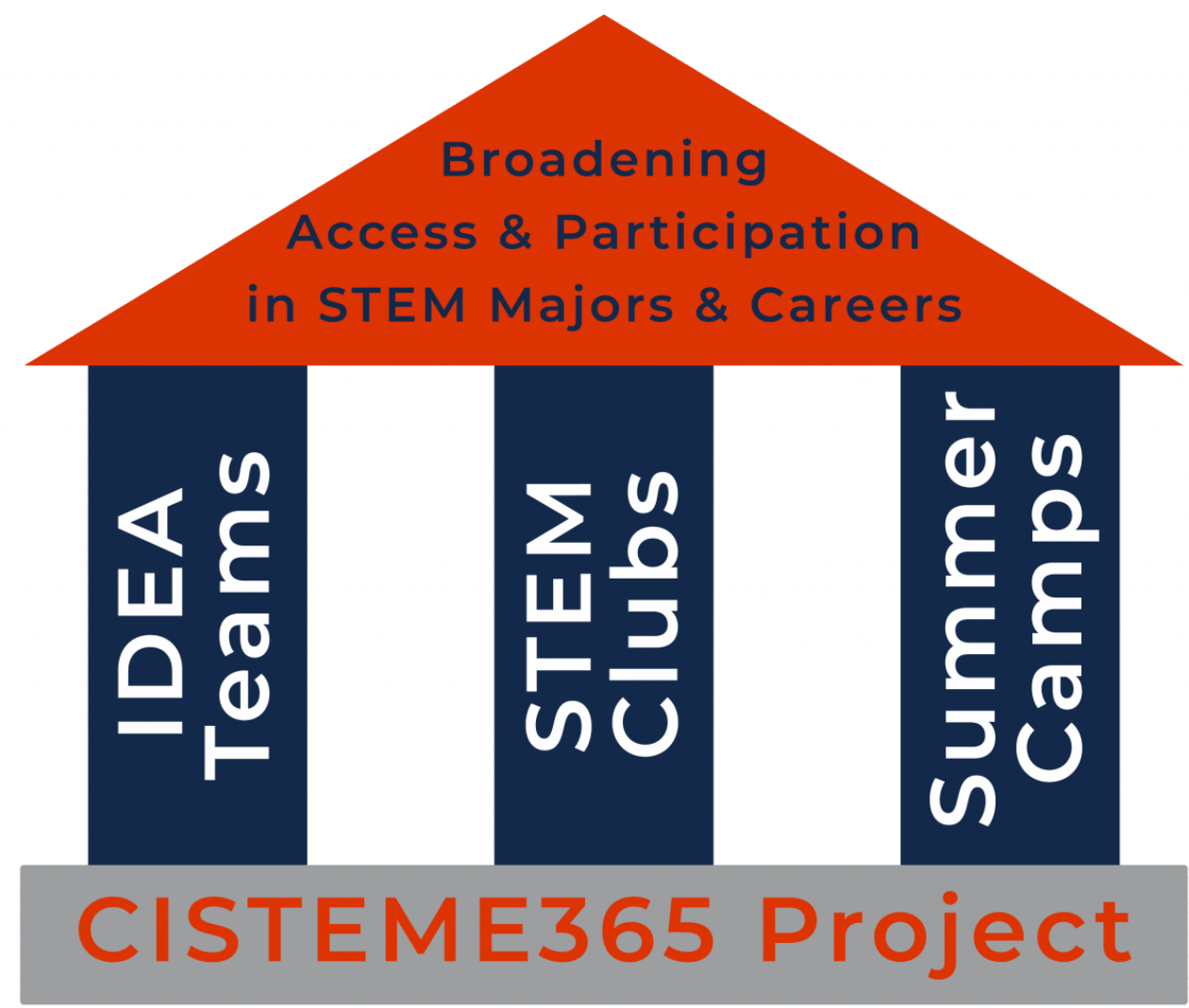


Figure 2.

The action research project template of the National Alliance for Partnerships in Equity

\begin{tabular}{|l|l|}
\hline AREP Title & \\
\hline Contributor(s) & \\
\hline Location & \\
\hline Class Periods & \\
\hline $\begin{array}{l}\text { Number of Students } \\
\text { Reached }\end{array}$ & \\
\hline Research Issue & \\
\hline Strategies Applied & \\
\hline Results & \\
\hline
\end{tabular}

